\title{
RADIATION ENVIRONMENT AT ISOL TARGET STATION OF RARE ISOTOPE FACILITY*
}

\author{
M.A. Kostin\#, I. Baek, V. Blideanu, G. Bollen, D.E. Lawton, R.M. Ronningen, \\ NSCL, MSU, East Lansing, MI 48824 \\ D.J. Vieira, LANL, Los Alamos, NM 87545 \\ L.E. Ahle, S. Reyes, K.L.Whittaker, LLNL, Livermore, CA 94550 \\ T.W. Burgess, D.L. Conner, T.A. Gabriel, I. Remec, ORNL, Oak Ridge, TN 37831
}

\begin{abstract}
Next-generation exotic beam facilities will offer several approaches to produce rare isotopes far from stability. One approach is Isotope Separation On-line, ISOL, which is the isotope production by interactions of light ion beams with heavy nuclei of targets. A pre-conceptual design of an ISOL target station was done as part of the research and development work for the Rare Isotope Accelerator, RIA. This report summarizes results of radiation calculations for the RIA ISOL target station. This includes radiation effects such as prompt radiation at the target station and from neutron sky-shine, activation of ground water, air, and components.
\end{abstract}

\section{ISOL TARGET STATION CONCEPT}

A next-generation exotic beam facility is expected to produce a broad range of rare isotopes that would be available for research in nuclear physics and nuclear astrophysics. The rare isotopes can be produced trough a variety of methods, one of which is Isotope Separation On-line, ISOL. The ISOL method utilizes light ion beams interacting with heavy nuclear of target, and produces isotopes through the processes of spallation and fission. A typical ISOL target is bulk in order to maximize the number of beam collisions in the target and hence the number of produced isotopes. The target is kept at a high temperature in order to extract the isotopes from it. The extracted isotopes are ionized and directed to a preseparator, and then could be sent to stopped beam areas, or to a post-accelerator, or can be further purified in a high-resolution separator. Since the ISOL method involves bulk targets, only chemically favorable isotopes with relatively long half-lives can be extracted in sufficient quantities due to chemical reactions and decay during the extraction. On the other hand, an advantage of the method is that it provides rare isotope beams of high intensities.

The results summarized in this report have been obtained as part of the RIA R\&D program. An ISOL target station prototype similar to that used in TRIUMF was selected for these studies. The central piece of the station is a vacuum tank containing modules with beam instrumentation, a target, two beam dumps, and an extraction ion channel (see Fig. 1). The modules can be serviced independently. The tank is placed in a pit with

\footnotetext{
*Work supported by DOE grant DE-FG02-04ER41322

${ }^{*}$ kostin@nscl.msu.edu
}

massive walls of iron and concrete for radiation protection purposes.

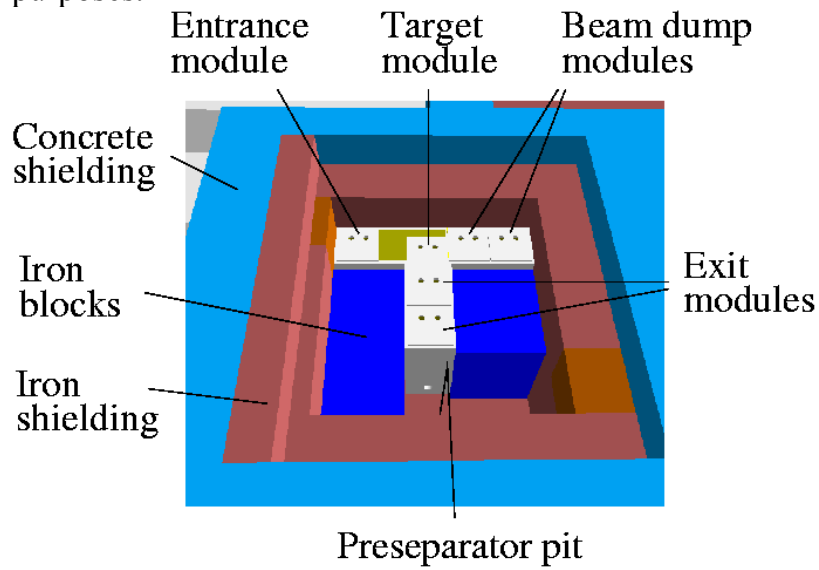

Figure 1: 3-D view of the model of the ISOL target station. The top layer of shielding is removed.

A significant challenge of RIA ISOL is a beam power of $400 \mathrm{~kW}$ it has to withstand. This is up to 10 times more than that for any similar station currently operating. That much beam power will create significant radiation doses at the target station, and will result in short lifetimes of various components of the station due to the severe radiation damage.

Although beams of $\mathrm{p}, \mathrm{d}$ and ${ }^{3} \mathrm{He}$ are considered for RIA ISOL, all the calculations presented here were carried out with $1 \mathrm{GeV} / \mathrm{c}$ proton beam and a beam power of $400 \mathrm{~kW}$.

\section{PROMPT RADIATION EFFECTS}

\section{Prompt Dose in Service Building}

The ISOL station would be located in a service building, and would be surrounded with massive shielding blocks. High levels of radiation will forbid personnel to be in the building during operation, and thus the amount of the radiation shielding over the station is driven by the equipment lifetime, primarily by the lifetime of service cranes. Prompt doses were calculated with the MARS15 code [1]. The model used is comprised of $1 \mathrm{~m}$-thick pit ceiling blocks of cast iron (not shown in Fig. 1). In addition, the top $1.6 \mathrm{~m}$ of every module is of cast iron with two $\varnothing 6$-inch dogleg-shaped conduits for utility lines. Our studies indicated that additional iron shielding blocks placed inside the pit was a valuable addition to the model. The blocks (shown in blue in Fig. 1) intercept neutrons produced in the target and beam dump modules that 
otherwise could reach the pit ceiling and increase the dose in the service building by approximately an order of magnitude. The calculations found that the maximum dose equivalent rate in the building averaged over a tissue equivalent phantom was $11,574 \pm 262 \mathrm{mrem} / \mathrm{hr}$.

\section{Prompt Dose in Downstream Area}

The service building could be adjacent to a storage or office area. The DOE regulatory requirements limit the dose equivalent rate to $0.25 \mathrm{mrem} / \mathrm{hr}$ for areas with unlimited occupancy. The dose equivalent rate was calculated outside of the service building downstream of the ISOL target station. In our model the axis of incoming beam and the normal to the building wall form an angle of $30^{\circ}$. The space between the station and the building wall is filled with concrete shielding blocks, so that the total amount of radiation shielding along the beam axis comprises $1 \mathrm{~m}$ of cast iron and $6 \mathrm{~m}$ of concrete. Our calculations showed that the above amount of shielding reduced the dose equivalent rate to $100 \mathrm{mrem} / \mathrm{hr}$ on the beam axis. One should note that adding extra shielding could mitigate the dose in the occupied areas.

The target station will be equipped with a pre-separator dipole and will have an outlet downstream of the "preseparator pit' as it is marked in Fig. 1. The dose equivalent rate in the outlet outside the building is high due to the open space of the outlet and reaches a level of $10^{6} \mathrm{mrem} / \mathrm{hr}$.

\section{Neutron Sky-shine}

It is obvious that some of the neutrons produced in the target station will penetrate through the shielding and the service building walls and the roof. Since the interaction length in air of such neutrons is about $700 \mathrm{~m}$, they will create enhanced radiation at significant distances from the building at the ground level by means of scattering back from the nuclei of air. This effect is known as neutron sky-shine. The effect was studied with a model that consists of the service building and surrounding air in addition to the target station. The building in the model is a concrete box with walls of a variable thickness of 0.7$1.5 \mathrm{~m}$ and with $0.5 \mathrm{~m}$-thick concrete ceiling. The surrounding air extents $2.5 \mathrm{~km}$ upward and sideward. It was assumed that the air did not contain water and that the density of air did not change with the altitude. The following conclusions can be made from the calculations: the resulting prompt dose distribution at the ground level is roughly circular, centered at the service building; the prompt dose equivalent rate is $0.01 \mathrm{mrem} / \mathrm{hr}$ at a distance of $\sim 200 \mathrm{~m}$ from the building and decreasing by an order of magnitude every $\sim 500 \mathrm{~m}$. This level of radiation can be adjusted by changing the shielding thickness over the target station.

\section{RESIDUAL RADIATION EFFECTS}

\section{Ground Water Activation}

Operating the ISOL target station would have a potential to activate soil and ground water in the vicinity of the beam enclosure. It is anticipated that the activated water will be pumped out from the underneath of the target station and will be discharged onto the ground surface. The activated water will have to meet US EPA and DOE regulatory standards for the concentration of radionuclides [2]. Typically only ${ }^{3} \mathrm{H}$ and ${ }^{22} \mathrm{Na}$ are of concern. The sum of the fractions of radionuclide contamination must be less than the unity, i.e.

$$
\Sigma \mathrm{C}_{\mathrm{i}} / \mathrm{C}_{\mathrm{i}, \text { reg }} \leq 1,
$$

where $C_{i}$ is the concentration of a given radionuclide and $\mathrm{C}_{\mathrm{i} \text {,reg }}$ is the maximum allowed concentration in surface water, with $\mathrm{C}_{\mathrm{i}, \text { reg }}=2000 \mathrm{pCi} / \mathrm{ml}$ for ${ }^{3} \mathrm{H}$ and $10 \mathrm{pCi} / \mathrm{ml}$ for ${ }^{22} \mathrm{Na}$. Drinking water concentration limits are $20 \mathrm{pCi} / \mathrm{ml}$ and $0.4 \mathrm{pCi} / \mathrm{ml}$ respectively.

The activation of ground water can be studied through the star density in soil, which can be converted to radionuclide concentration using many site-specific factors. The star density in soil was calculated with $1 \mathrm{~m}$ of cast iron and $3 \mathrm{~m}$ of solid concrete shielding under the vacuum tank. In our studies, we assumed that the geological environment is similar to that at Fermilab. That allowed us a direct comparison of our results with those for already existing and operating machines on the FNAL site. Our calculations showed that the maximum star density under the target station would be $556 \pm 9 \mathrm{~cm}^{-3} \mathrm{sec}^{-1}$ or $(1.11 \pm 0.02) \times 10^{10} \mathrm{~cm}^{-3} \mathrm{yr}^{-1}$, assuming that the operational year is $2 \times 10^{7} \mathrm{sec}$. This density is more than a factor of 5 below a density of $5.96 \times 10^{10} \mathrm{~cm}^{-3} \mathrm{yr}^{-1}$, limit used in the design of the beam line of the experiment MIPP at FNAL [3].

\section{Air Activation}

As it has been shown in [4], the principal source of radioactivity in air at accelerators is due to the production of radionuclides in interactions of primary and secondary particles with target nuclei in air. The air activity can be calculated using an approximate method described in [4], [5]. The method derives the total specific activity as a function of neutron flux with the energy above $20 \mathrm{MeV}$ and air circulation expressed in number of air exchanges per hour. The air circulation can be used to suppress the build-up of long-lived radionuclides and to cool down the shielding. There are two distinctive air volumes in the studied system - air in the target pit and air in the service building. The neutron flux was calculated for both the volumes. It is $\mathrm{F}_{\mathrm{n}}(>20 \mathrm{MeV})=3.78 \times 10^{8} \mathrm{~cm}^{-2} \mathrm{sec}^{-1}$ for the target pit and $F_{n}(>20 \mathrm{MeV})=2.23 \times 10^{2} \mathrm{~cm}^{-2} \mathrm{sec}^{-1}$ for the service building. With the calculated neutron flux, the specific activity was examined as a function of air circulation (see Figs. 2, 3).

DOE has established Derived Activity Concentrations (DACs) for radiation workers [6]. The activity concentration of 1 DAC corresponds to the receipt of 5000 mrem of dose equivalent if a worker spends the entire working year in the radioactive air. Similar to DAC, values of Derived Concentration Guides (DCGs) have been established for members of the general public. DCGs 
are based on the receipt of 100 mrem of dose equivalent by an individual who spends all of the time in one year breathing such air [2]. DAC and DCG are represented through maximum allowed concentration, $\mathrm{C}_{\max }$, of certain radionuclides in air in a similar way as for the ground water activation [4] (see Eq. 1). $\mathrm{C}_{\max }$ for ${ }^{11} \mathrm{C},{ }^{13} \mathrm{~N},{ }^{15} \mathrm{O}$ that corresponds to $1 \mathrm{DAC}$ is $4 \mu \mathrm{Ci} / \mathrm{m}^{3}$ (shown as a horizontal red line in Fig. 2). $\mathrm{C}_{\max }$ that corresponds to $1 \mathrm{DCG}$ for the above radionuclides is $0.02 \mu \mathrm{Ci} / \mathrm{m}^{3}$. Fig. 2 shows, that the number of air exchanges per hour needed to bring the activity concentration in the target pit below the level of 1 $\mathrm{DAC}$ is very large and most likely cannot be realized in practice, and thus air in the pit must circulate in a closed loop. The activity concentration in the service building (see Fig. 3) is close to the level of 1 DCG, meaning that the air might not be simply released and should be kept in specially designated tanks to allow the activity to decay away.

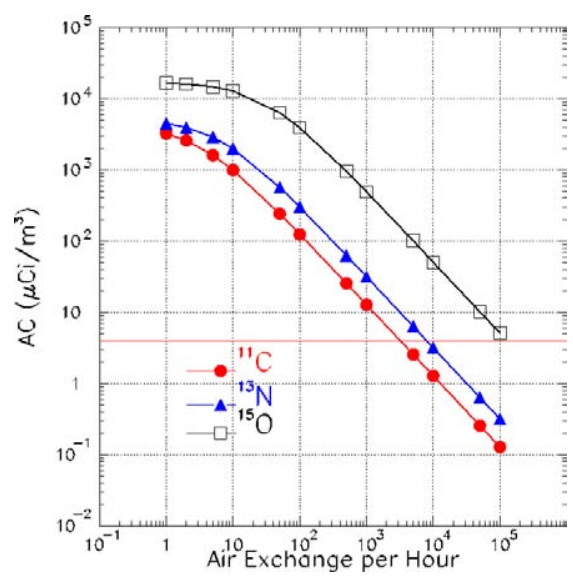

Figure 2: Activity concentration in air in the target pit. The horizontal line shows an activity concentration corresponding to $1 \mathrm{DAC}$.

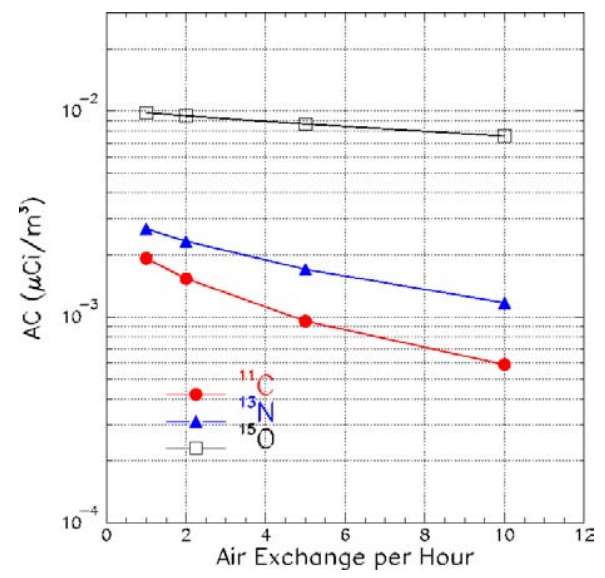

Figure 3: Activity concentration in air in the service building.

\section{Activation of Top Shielding and Equipment in Target Pit}

It is desirable to keep the dose equivalent rates from activated components below a level of $100 \mathrm{mrem} / \mathrm{hr}$, i.e. below the "High Radiation Area" limit, so that radiation workers could be permitted to perform "hands-on" maintenance work. The residual dose equivalent rates are determined after 100 days of irradiation, 4 hours after shut down and at a distance of $30 \mathrm{~cm}$ (" 100 days / 4 hours / 30 $\mathrm{cm}$ "). This is numerically similar to one of " 30 days / 1 day / 0cm" [7]. The residual dose equivalent rate was calculated for the top portion of target shielding and was found to be $0.46 \pm 0.03 \mathrm{mrem} / \mathrm{hr}$. Access will also be required to the top portion of the vacuum tank where various instrumentation will be placed, such as vacuum pumps and motors. Residual dose equivalent rates "30 days / 1 day / $0 \mathrm{~cm}$ " and absorbed dose rates were calculated for the above location for a variety of materials. The doses are summarized in Table 1. Some of materials would be highly activated with residual dose equivalent rates above $100 \mathrm{mrem} / \mathrm{hr}$. The problem can be corrected by extending the shielding (top) part of the modules.

Table 1: Residual dose equivalent rates, $\mathrm{P} \gamma$, and absorbed dose rates, $\mathrm{AD}$, for materials placed over the vacuum tank

\begin{tabular}{|l|l|l|}
\hline Material & $\mathbf{A D}(\mathbf{k G y} / \mathbf{y r})$ & $\mathbf{P}_{\gamma}(\mathbf{m r e m} / \mathbf{h r})$ \\
\hline Ceramic $\left(\mathrm{Al}_{2} \mathrm{O}_{3}\right)$ & 24.3 & 252 \\
\hline Copper & 26.7 & 855 \\
\hline Iron & 11.9 & 163 \\
\hline Teflon $\left(\mathrm{CF}_{2}\right)$ & 17.6 & 10.5 \\
\hline G10 & 83.6 & 0.7 \\
\hline Insulation $(\mathrm{MgO})$ & 23.4 & 1079 \\
\hline Perm. Magnet $\left(\mathrm{Sm}_{2} \mathrm{Co}_{17}\right)$ & 31.4 & 28.4 \\
\hline EPDM rubber $\left(\mathrm{C}_{10} \mathrm{H}_{18}\right)$ & 52.8 & 3.48 \\
\hline
\end{tabular}

\section{SUMMARY}

Although operating the ISOL target station with a 400 $\mathrm{kW}$ beam may be a significant challenge, our studies showed that the radiological aspects of operation, such as prompt dose, activation of ground water and air, and activation of components, can be controlled with carefully designed radiation shielding and air handling systems.

\section{REFERENCES}

[1] N.V. Mokhov, "The Mars Code System User's Guide”, Fermilab-FN-628 (1995).

[2] U.S. Department of Energy Order 5400.5 (1990).

[3] M.A.Kostin, "MARS Calculations for MIPP (FNALE907) Shielding Assessment", http://ppd.fnal.gov /experiments/e907/Beam/sas.pdf (2003).

[4] J. Donald Cossairt, "Radiation Physics for Personnel and Environment Protection", FERMILAB-TM-1834 (Nov 1993)

[5] H.W. Patterson, R.H. Thomas, "Accelerator Health Physics", Academic Press, New York (1973)

[6] United States Code of Federal Regulations, Title 10 Part 835 (1993); Title 40 Parts 9, 141 and 142 (2000).

[7] O.E. Krivosheev, N.V. Mokhov, "Tolerable beam loss at high intensity proton machines", FERMILABCONF-00-192 (Aug 2000). 